\title{
Successful Treatment of Syndrome of Inappropriate Antidiuretic Hormone Secretion Associated with Neuro-Sweet Disease in Myelodysplastic Syndrome
}

\author{
Satoko Oka ${ }^{1}$, Kazuo Ono ${ }^{2}$ and Masaharu Nohgawa ${ }^{1}$
}

\begin{abstract}
:
Sweet disease may occur in several organs, and central nervous system involvement, known as NeuroSweet disease (NSD), is rare. The clinical features of NSD include recurrent encephalomeningitis accompanied by fever and erythematous plaques; systemic corticosteroid therapy is highly effective. Syndrome of inappropriate antidiuretic hormone secretion (SIADH) is an important electrolyte abnormality because it can be life-threatening. We describe the first case of SIADH and NSD associated with low-risk myelodysplastic syndrome that was successfully treated with corticosteroids and cyclosporine. The patient has remained stable for 1 year without any recurrence.
\end{abstract}

Key words: Neuro-Sweet disease (NSD), myelodysplastic syndrome (MDS), syndrome of inappropriate antidiuretic hormone secretion (SIADH)

(Intern Med 57: 595-600, 2018)

(DOI: 10.2169/internalmedicine.9215-17)

\section{Introduction}

Sweet disease (SD) is a systemic disease characterized by fever, peripheral blood leukocytosis, and tender, elevated, erythematous plaques on the face, extremities, and other locations. SD is classically divided into three categories: classical or idiopathic, drug-induced, and malignancy-associated SD (1). Previous studies have reported a relationship between SD and myelodysplastic syndrome (MDS) (2-5). Although the pathogenesis of SD currently remains unknown, elevated levels of interleukin (IL)-6 support the pathogenetic role of pro-inflammatory cytokines (6).

SD may occur in several organs, and central nervous system involvement, known as Neuro-Sweet disease (NSD), is rare, but is more common in Asian patients (7). Patients present with painful erythematous plaques on their skin, and a histological examination of these plaques shows the dense dermal infiltration of neutrophils with no signs of vasculitis. The frequencies of human leukocyte antigen (HLA)-B54 and $\mathrm{Cw} 1$ have been reported to be high in Japanese patients with NSD, with HLA-B51-negativity related to Behçet's disease (BD) (8). Encephalitis and meningitis are common neurological manifestations of NSD. Although systemic corticosteroid therapy is highly effective for NSD, symptoms frequently relapse (9).

Syndrome of inappropriate antidiuretic hormone secretion (SIADH) is an important electrolyte abnormality because it can be life-threatening. The general causes of SIADH include various neurological disorders and neurosurgical procedures (10), malignancies (11), and drugs (12). In the present case, SIADH developed with the recurrence of NSD, and improved after second-line treatment for NSD; thus, cytokines such as interleukin (IL)-6 may be associated with NSD and SIADH.

NSD is rare, and no cases of SIADH associated with NSD have previously been reported. We herein describe a case of SIADH and NSD associated with MDS that was successfully treated with corticosteroids and cyclosporine.

${ }^{1}$ Division of Hematology, Japanese Red Cross Society Wakayama Medical Center, Japan and ${ }^{2}$ Division of Pathology, Japanese Red Cross Society Wakayama Medical Center, Japan

Received: March 22, 2017; Accepted: July 22, 2017; Advance Publication by J-STAGE: December 8, 2017

Correspondence to Dr. Satoko Oka, okas@jasmine.ocn.ne.jp 
Table. Laboratory Data before Admission, and during 2 episodes of NSD.

\begin{tabular}{lccc}
\hline & Before admission & 1st spisode (day 0) & 2nd episode(day 30) \\
\hline WBC $\left(\times 10^{9} / \mathrm{L}\right)$ & 2.3 & 3.7 & 3.7 \\
RBC $\left(\times 10^{10} / \mathrm{L}\right)$ & 372 & 299 & 346 \\
$\mathrm{Hb}(\mathrm{g} / \mathrm{dL})$ & 11.5 & 9.2 & 10.4 \\
$\mathrm{Plt}\left(\times 10^{9} / \mathrm{L}\right)$ & 11.2 & 193 & 183 \\
$\mathrm{AST}(\mathrm{IU} / \mathrm{L})$ & 12 & 30 & 17 \\
$\mathrm{ALT}(\mathrm{IU} / \mathrm{L})$ & 14 & 22 & 18 \\
$\mathrm{LDH}(\mathrm{IU} / \mathrm{L})$ & 250 & 258 & 215 \\
$\mathrm{BUN}(\mathrm{mg} / \mathrm{dL})$ & 15 & 19 & 7 \\
$\mathrm{Cre}(\mathrm{mg} / \mathrm{dL})$ & 0.45 & 0.67 & 0.4 \\
$\mathrm{UA}(\mathrm{mg} / \mathrm{dL})$ & 4 & 5.5 & 1 \\
$\mathrm{Glc}(\mathrm{mg} / \mathrm{dL})$ & 101 & 102 & 110 \\
Na $(\mathrm{mEq} / \mathrm{L})$ & 133 & 141 & 124 \\
$\mathrm{~K}(\mathrm{mEq} / \mathrm{L})$ & 4.3 & 4.3 & 3.9 \\
Cl $(\mathrm{mEq} / \mathrm{L})$ & 105 & 106 & 94 \\
$\mathrm{CRP}(\mathrm{mg} / \mathrm{dL})$ & 0.31 & 20.9 & 13.2 \\
\hline
\end{tabular}

NSD: Neuro-Sweet disease, WBC: white blood cell, RBC: red blood cell, Hb: hemoglobin, Plt: platelet, AST: aspartate aminotransferase, ALT: alanine aminotransferase, LDH: lactate dehydrogenase, BUN: blood urea nitrogen, Cre: creatinine, UE: uric acid, Glu: glucose, CRP: Creactive protein
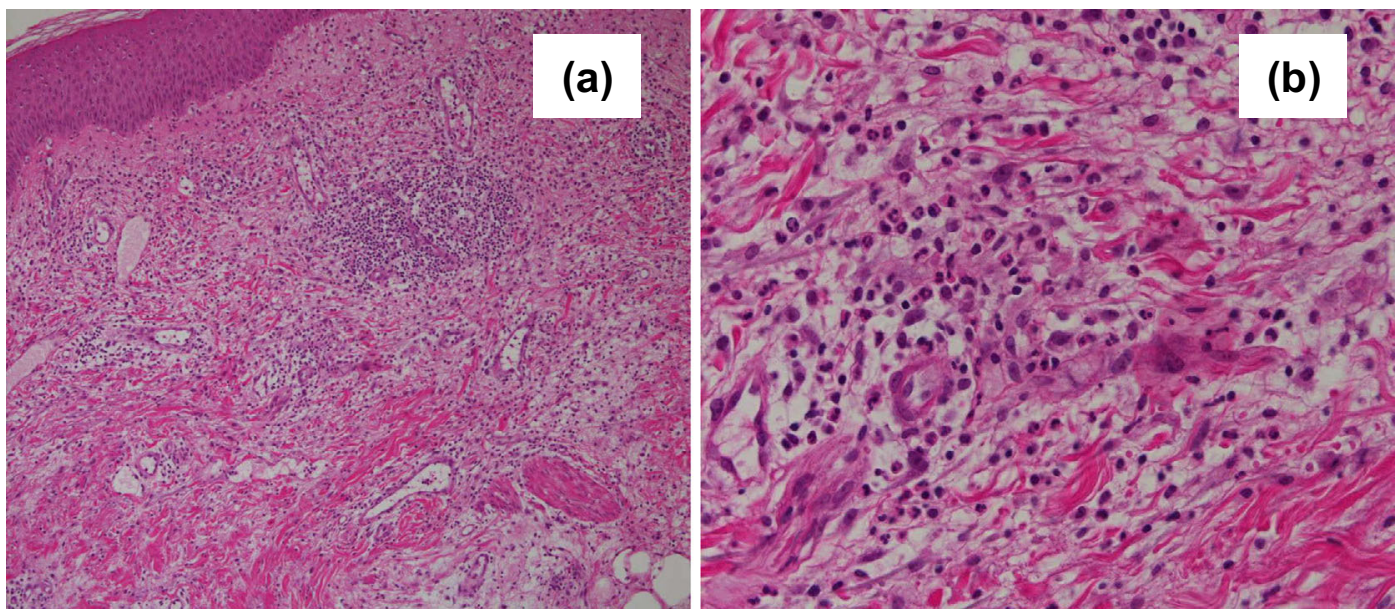

Figure 1. A skin biopsy specimen showed predominantly neutrophilic infiltration of the dermis [Hematoxylin and Eosin staining, (a) $\times 50,(b) \times 100]$.

\section{Case Report}

A 66-year-old Japanese woman with a 6-year history of MDS [refractory anemia (RA), International Prognostic Scoring System: low] presented with fever and a rash over both legs. The patient had no history of respiratory infection. Laboratory tests showed no abnormalities (Table). Skin biopsy revealed predominantly neutrophilic infiltration of the dermis and the absence of leukocytoclastic vasculitis (Fig. 1). She was diagnosed with SD. Prednisolone $(40 \mathrm{mg} /$ day) was administered for seven days, which resulted in the disappearance of her symptoms; thereafter, the dose was tapered.

At 9 months after the onset of SD, the patient visited our hospital with fever of 3 days in duration, while being treated with prednisolone $(10 \mathrm{mg} /$ day). On admission, her temperature was $38.6^{\circ} \mathrm{C}$ and blood pressure was $104 / 67 \mathrm{mmHg}$. There were no remarkable features in the heart, lungs, or abdomen. A neurological examination revealed consciousness disturbance [Japan Coma Scale (JCS) I-3]. The patient's tendon reflexes were normal, and no pathological reflexes were noted. Nuchal rigidity and Kernig's sign were negative. The patient demonstrated no abnormal ocular signs, including episcleritis and uveitis.

Laboratory tests revealed the following: white blood cell (WBC) count, $3.7 \times 10^{9} / \mathrm{L}$; neutrophil cell count, $2.0 \times 10^{9} / \mathrm{L}$; red blood cell $(\mathrm{RBC})$ count, $299 \times 10^{10} / \mathrm{L}$; hemoglobin $(\mathrm{Hb})$ concentration, $9.2 \mathrm{~g} / \mathrm{dL}$; and platelet count, $193 \times 10^{9} / \mathrm{L}$. Her serum sodium concentration was $141 \mathrm{mEq} / \mathrm{L}$ (normal range: $135-150 \mathrm{mEq} / \mathrm{L}$ ), her creatinine level was $0.51 \mathrm{mg} / \mathrm{dL}$ (normal range: $0.40-0.80 \mathrm{mg} / \mathrm{dL}$ ) and her C-reactive protein 


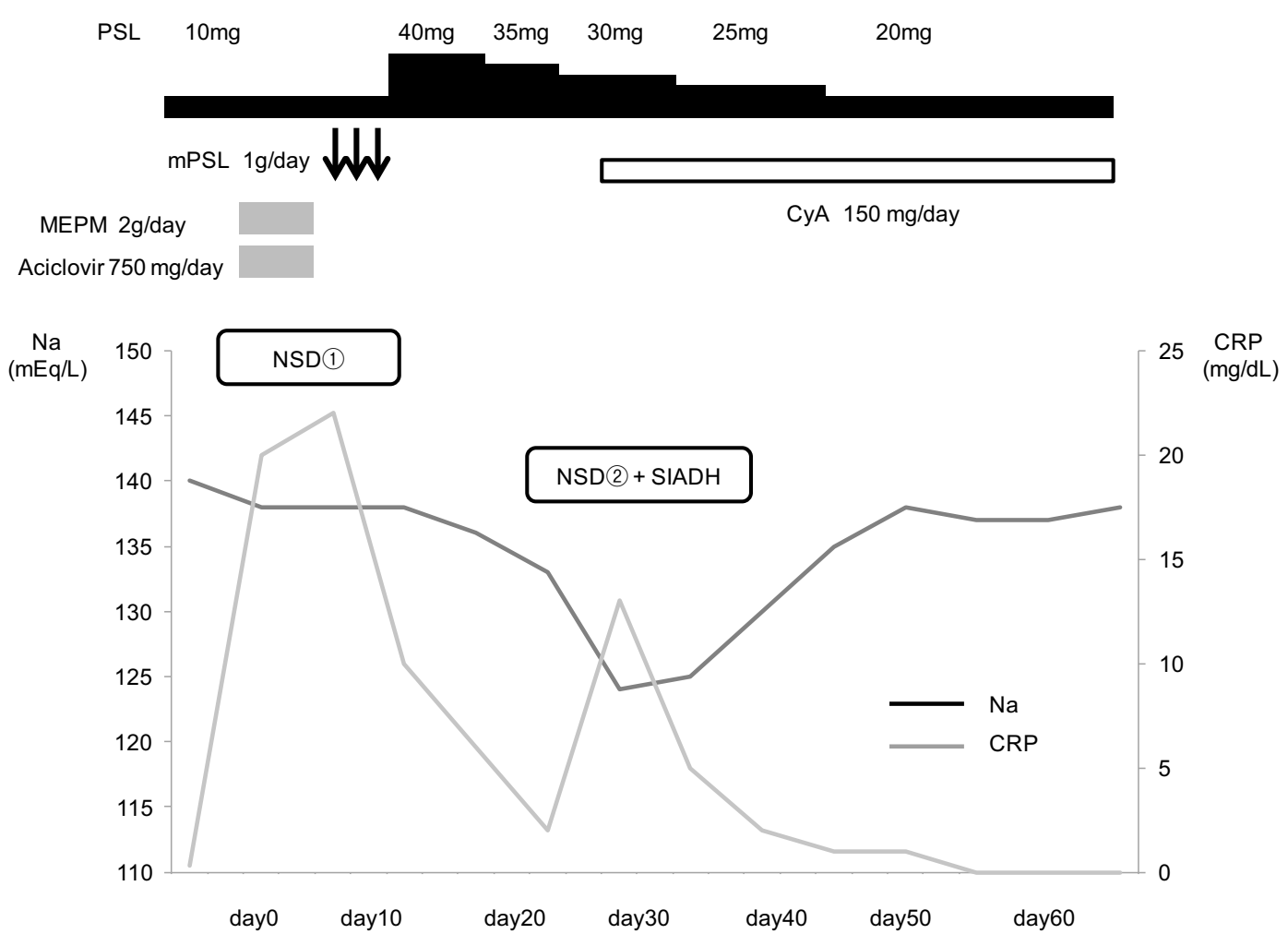

Figure 2. The CRP and serum Na levels before and after treatment. CRP: C-reactive protein

(CRP) level was $20.9 \mathrm{mg} / \mathrm{dL}$ (normal range: lower than 0.30 $\mathrm{mg} / \mathrm{dL}$ ) (Table, Fig. 2). The patient was negative for serum rheumatoid factor and antibodies including antinuclear, antiSS-A, anti-SS-B, anti-DNA, anti-Sm, and anti-RNP antibodies, perinuclear anti-neutrophil cytoplasmic antibodies, and cytoplasmic anti-neutrophil cytoplasmic antibodies. A cerebrospinal fluid (CSF) examination revealed a normal initial pressure, as well as the following findings: cell count, $50 / \mu \mathrm{L}$ (45 monocytes and 5 polymorphs); protein, $130 \mathrm{mg} / \mathrm{dL}$; and glucose, $40 \mathrm{mg} / \mathrm{dL}$ (blood glucose, $102 \mathrm{mg} / \mathrm{dL}$ ). Brain magnetic resonance imaging (MRI) revealed no abnormal signals. She was initially suspected of having bacterial or viral meningitis; thus, an intravenous drip infusion of meropenem (3 g/day) and acyclovir (1,200 $\mathrm{mg} /$ day) was initiated (Fig. 2). However, the patient's fever did not improve and her level of consciousness deteriorated to JCS II-20. A CSF culture was negative for Mycobacterium tuberculosis and fungi. Antibodies against herpes simplex virus and varicella zoster virus were negative, and a polymerase chain reaction (PCR) was negative for herpes simplex virus and varicella zoster virus. On day 10, she was found to be negative for HLA-B51, but positive for HLA-B54 and HLA-Cw1, which suggested NSD. Thus, steroid pulse therapy with methylprednisolone (1 g/day) was administered for three days. Her neurological symptoms gradually improved (JCS I-1) with a decrease in her CRP level, and the dose of prednisolone was tapered to $30 \mathrm{mg} /$ day on day 26 (Fig. 2). On day 30, she presented with fever $\left(38.5^{\circ} \mathrm{C}\right)$ and her level of consciousness deteriorated to JCS II-10. Laboratory tests showed the following: WBC count, $3.5 \times 10^{9} / \mathrm{L}$; neutrophil count, $1.7 \times 10^{9} / \mathrm{L}$; RBC count, $346 \times 10^{10} / \mathrm{L}$; Hb concentration, $10.4 \mathrm{~g} / \mathrm{dL}$; plate- let count, $183 \times 10^{9} / \mathrm{L}$; creatinine level, $0.40 \mathrm{mg} / \mathrm{dL}$ and CRP level, $13.2 \mathrm{mg} / \mathrm{dL}$. The patient's serum sodium level rapidly decreased to $124 \mathrm{mEq} / \mathrm{L}$ with a urine sodium level of 40 $\mathrm{mEq} / \mathrm{L}$, serum osmolality of $266 \mathrm{mOsmol} / \mathrm{kg} \mathrm{H}_{2} \mathrm{O}$ (normal range: $275-290 \mathrm{mOsmol} / \mathrm{kg}$ ), and urine osmolality of 581 $\mathrm{mOsmol} / \mathrm{kg} \mathrm{H} \mathrm{H}_{2} \mathrm{O}$ (normal range: $50-1,300 \mathrm{mOsmol} / \mathrm{kg}$ ) without the suppression of antidiuretic hormone (ADH) $(3.2 \mathrm{mg} /$ $\mathrm{dL}$ ). The patient's renal, thyroid, and adrenal functions were normal. Her serum IL-6 level was $213 \mathrm{pg} / \mathrm{mL}$ (normal range: lower than $4 \mathrm{pg} / \mathrm{mL}$ ). A CSF examination revealed a normal initial pressure, as well as the following findings: cell count, $70 / \mu \mathrm{L}$ (60 monocytes and 10 polymorphs); protein, $209 \mathrm{mg} / \mathrm{dL}$; and glucose level, $28 \mathrm{mg} / \mathrm{dL}$ (blood glucose, $110 \mathrm{mg} / \mathrm{dL})$. MRI revealed the absence of high intensity signals in the posterior pituitary lobe on sagittal T1weighted images (Fig. 3a) and normal intensity in the hypothalamus on axial fluid-attenuated inversion recovery images (Fig. 3b). A bone marrow aspirate sample showed normal cellularity with no increase in blasts or hypoplasia of the erythroid lineage. Neither nuclear p53 nor CD34 immunostaining was detected in hematopoietic cells. A karyotypic analysis revealed 46,XX (20/20 cells). The patient did not exhibit any evidence of dehydration or heart failure.

The patient was diagnosed with SIADH, which was associated with the recurrence of NSD. The administration of cyclosporine was initiated at a dose of $150 \mathrm{mg} / \mathrm{day}$, as second-line therapy in combination with prednisolone and $3 \%$ sodium chloride (Fig. 2). On day 45, the patient's neurological symptoms improved, her CRP level normalized, and her serum sodium level was $136 \mathrm{mEq} / \mathrm{L}$ (serum osmolality, $279 \mathrm{mOsmol} / \mathrm{kg} \mathrm{H}_{2} \mathrm{O}$; and urine osmolality, $340 \mathrm{mOs}-$ 


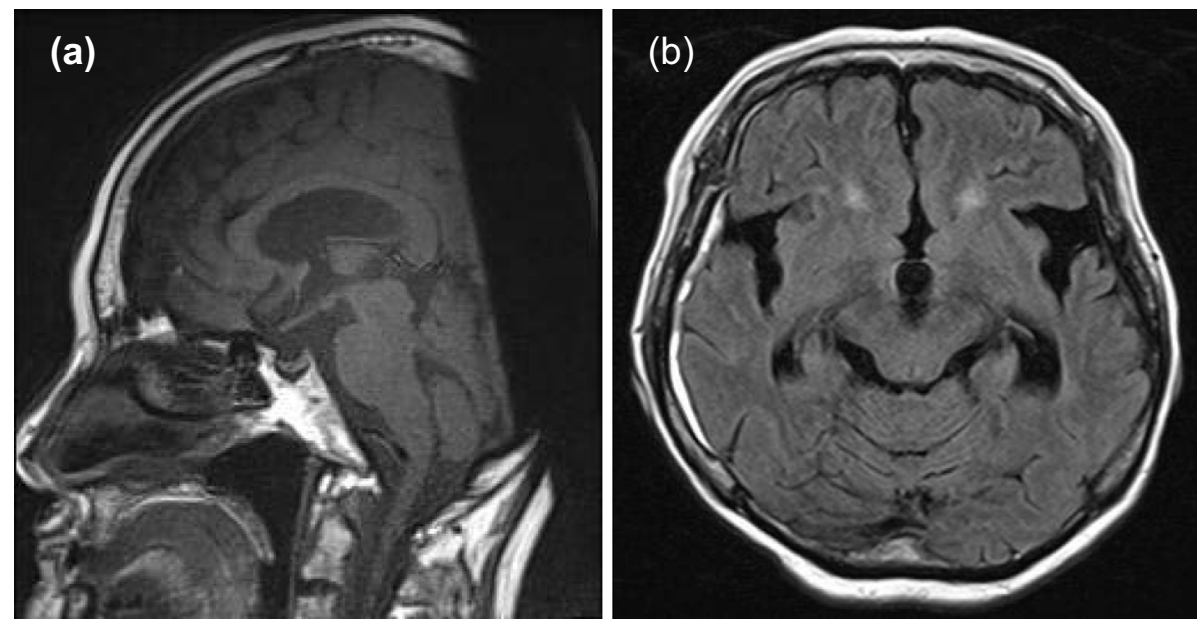

Figure 3. The MRI findings. (a) Sagittal T1 weighted images from brain MRI showed the absence of high intensity signals in the posterior pituitary lobe. (b) Axial fluid-attenuated inversion recovery (FLAIR) images showed normal signals in the hypothalamus.

mol/ $/ \mathrm{kg} \mathrm{H}_{2} \mathrm{O}$ ) (Table). Her serum IL-6 level was $6 \mathrm{pg} / \mathrm{mL}$.

Recurrence was not detected and the patient was discharged on day 70. The patient's condition has remained stable for 1 year without recurrence with the administration of cyclosporine (200 mg/day) and prednisolone ( $5 \mathrm{mg} /$ day).

\section{Discussion}

NSD has been identified as SD with CNS involvement characterized by multisystem neutrophilic infiltration. A patient with MDS (RA) presented with cutaneous manifestations of SD, and subsequently showed aseptic meningitis, which was compatible with a diagnosis of probable NSD, according to the criteria proposed by Hisanaga et al. (7). The patient's clinical features are summarized as follows: recurrent encephalomeningitis accompanied by fever, erythematous plaques on the legs, which histologically showed predominantly neutrophilic infiltration of the dermis, the absence of leukocytoclastic vasculitis, cutaneous vasculitis, and thrombosis, which are present in $\mathrm{BD}$, and positivity for HLA-B54 and Cw1, but negativity for $\operatorname{HLA-B51}(7,8)$.

In addition to occurring in the dermis, SD may occur in other organs, including the eyes, lungs, liver, kidneys, gastrointestinal tract, bone marrow, and muscles, even in the absence of skin lesions. NSD is rare and may present with different manifestations, such as aseptic meningitis, encephalitis, brainstem lesions, CSF changes, and psychiatric symptoms. Laboratory investigations often reveal peripheral blood leukocytosis and elevated CRP levels, and CSF studies generally show a slight increase in protein and mild-to-moderate pleocytosis. However, in MDS patients with cytopenia or neutropenia, such as the present case, a laboratory analysis may not show obvious peripheral blood leukocytosis or pleocytosis in the CSF. The MRI findings may be normal or demonstrate abnormal signal intensities in various CNS regions, without site predilection (9). The initial presentation is generally typical skin lesions followed by neurological in- volvement after days, months, or years. However, cases with an opposite presentation or simultaneous skin and nervous involvement have also been reported.

SD is divided into three types: classical (or idiopathic), malignancy-associated, and drug-induced SD (1). Malignancy-associated SD, which accounts for only 15-20\% of cases of SD, is most often associated with hematological malignancies, particularly acute myeloid leukemia (AML) $(13,14)$. Previous studies have reported a relationship between SD and MDS (2-5), and noted that SD may occur as a paraneoplastic condition of MDS. A relationship between autoimmune disorders and MDS (15), as well as profound abnormalities in chemokines leading to a proinflammatory milieu in low-risk MDS, has been reported. Kulasekararaja et al. divided patients into two groups according to their clinical features: acute non-relapsing SD and chronic relapsing remitting SD (16), with the latter potentially associated with low-risk MDS. In the chronic relapsing remitting SD group, eruptions were associated with severe systemic upset, including fever, chills, lethargy, and debility (4), and although corticosteroids were effective, a reduction in the dose of prednisolone resulted in the relapse of SD.

In our case, the reduction of the dose of prednisolone resulted in the first occurrence of NSD; the patient had recurrent NSD with SIADH that required second-line therapy. SIADH is relatively rare, but occasionally life-threatening. Papapostolou et al. reported a relationship between SIADH and the absence of a normal hyperintense signal in the neurohypophysis on MRI (17). The general causes of SIADH include disorders of the central nervous system, such as meningitis and trauma, malignant disease, lung disease, and drugs (10-12). The elevation of serum IL-6, which activates $\mathrm{ADH}$ secretion and induces SIADH, may be one of the mechanisms involved (18). The recurrence of NSD has rarely been reported to cause hyponatremia or SIADH.

The pathogenesis of NSD remains unclear. Neutrophil and 
other inflammatory cell activities are influenced by many cytokines and chemokines. The pathogenesis of SD has been suggested to be driven by $\mathrm{T}$ helper cells through the production of cytokines, which were found to be significantly elevated in the serum of patients with SD (19). Moreover, Kimura et al. reported that the levels of Th1 cytokines, IL-6 and IL- 8 in the CSF were important markers of disease activity in patients with NSD (20). In the present case, the patient's serum IL-6 level increased when SIADH developed with the recurrence of NSD, and decreased after the treatment of NSD; thus, cytokines such as IL-6 may be associated with NSD and SIADH.

Systemic corticosteroids are a highly effective treatment for SD and NSD, while other drugs (potassium iodide, colchicine, dapsone, indomethacin, and cyclosporine) may be used as a second option (21). Although CNS involvement in SD is typically benign and transient, disease recurrence has been reported in 50\% of cases (9). Cyclosporine, a calcineurin inhibitor, mainly suppresses $\mathrm{T}$ cells by downregulating transcription factors and also represents a therapeutic agent for low-risk MDS. Thus cyclosporine was effective for the treatment of steroid-resistant NSD in our MDS patient.

In the present case, there were potential causative factors for SIADH other than NSD, including MDS and drugs. The relationship between malignancies such as MDS and SIADH was weak because the patient's MDS did not progress at the onset of NSD and because SIADH improved after the treatment of NSD. Furthermore, the patient was not treated with drugs responsible for SIADH (i.e., chemotherapeutic or antiepileptic agents). Other causative factors, such as pulmonary lesions or a massive water intake, were also excluded in this patient.

To the best of our knowledge, this is the first report of SIADH associated with NSD. Although SIADH is rarely associated with NSD, NSD may be casually related to this syndrome. An awareness of the possible neurological complications of NSD is important for avoiding unnecessary therapies for other forms of meningoencephalitis and for successful treatment with systemic corticosteroids. Moreover, since hyponatremia is the most commonly observed electrolyte disturbance, the identification of hyponatremia, the diagnosis of SIADH, and appropriate treatment result in clinical improvement. The present case reinforces the value of the early evaluation of neurological symptoms and hyponatremia to reach a diagnosis, to allow for the prompt initiation of appropriate treatment, and to achieve successful therapeutic management.

The authors state that they have no Conflict of Interest (COI).

\section{References}

1. von den Driesch P. Sweet's syndrome (acute febrile neutrophilic dermatosis). J Am Acad Dermatol 31: 535-556, 1994.

2. Reuss-Borst MA, Pawelec G, Saal JG, Horny HP, Müller CA, Waller HD. Sweet's syndrome associated with myelodysplasia: possible role of cytokines in the pathogenesis of the disease. Br $\mathrm{J}$ Haematol 84: 356-358, 1993.

3. Avivi I, Rosenbaum H, Levy Y, Rowe J. Myelodysplastic syndrome and associated skin lesions: a review of the literature. Leuk Res 23: 323-330, 1999.

4. Kakaletsis N, Kaiafa G, Savopoulos C, et al. Initially lymphocytic Sweet's syndrome in male patients with myelodysplasia: a distinguished clinicopathological entity? Case report and systematic review of the literature. Acta Haematol 132: 220-225, 2014.

5. Vignon-Pennamen MD, Juillard C, Rybojad M, et al. Chronic recurrent lymphocytic Sweet syndrome as a predictive marker of myelodysplasia: a report of 9 cases. Arch Dermatol 142: 11701176, 2006.

6. Cohen PR, Kurzrock R. Sweet's syndrome and cancer. Clin Dermatol 11: 149-157, 1993.

7. Hisanaga K, Iwasaki Y, Itoyama Y; Neuro-Sweet Disease Study Group. Neuro-Sweet disease: clinical manifestations and criteria for diagnosis. Neurology 64: 1756-1761, 2005.

8. Mizoguchi M, Matsuki K, Mochizuki M, et al. Human leukocyte antigen in Sweet's syndrome and its relationship to Behçet's disease. Arch Dermatol 124: 1069-1073, 1988.

9. Drago F, Ciccarese G, Agnoletti AF, Sarocchi F, Parodi A. Neuro sweet syndrome: a systematic review. A rare complication of Sweet syndrome. Acta Neurol Belg 2016 (Epub ahead of print).

10. Kawaguchi T, Takeuchi M, Kawajiri C, et al. Severe hyponatremia caused by syndrome of inappropriate secretion of antidiuretic hormone developed as initial manifestation of human herpesvirus-6associated acute limbic encephalitis after unrelated bone marrow transplantation. Transpl Infect Dis 15: E54-E57, 2013.

11. Chubachi A, Miura I, Hatano Y, Ohshima A, Nishinari T, Miura AB. Syndrome of inappropriate secretion of antidiuretic hormone in patients with lymphoma-associated hemophagocytic syndrome. Ann Hematol 70: 53-55, 1995.

12. Liamis G, Milionis H, Elisaf M. A review of drug-induced hyponatremia. Am J Kidney Dis 52: 144-153, 2008.

13. Goodfellow A, Calvert H. Sweet's syndrome and acute myeloid leukaemia. Lancet 2: 478-479, 1979.

14. Burton JL. Sweet's syndrome, pyoderma gangrenosum and acute leukaemia. Br J Dermatol 102: 239, 1980.

15. Mufti GJ, Figes A, Hamblin TJ, Oscier DG, Copplestone JA. Immunological abnormalities in myelodysplastic syndromes. I. Serum immunoglobulins and autoantibodies. Br J Haematol 63: 143-147, 1986.

16. Kulasekararaj AG, Kordasti S, Basu T, Salisbury JR, Mufti GJ, du Vivier AW. Chronic relapsing remitting Sweet syndrome--a harbinger of myelodysplastic syndrome. Br J Haematol 170: 649-656, 2015.

17. Papapostolou C, Mantzoros CS, Evagelopoulou C, Moses AC, Kliifield J. Imaging of the sella in thesyndrome of inappropriate secretion of antidiuretic hormone. J Intern Med 237: 181-185, 1995.

18. Gionis D, Ilias I, Moustaki M, et al. Hypothalamic-pituitaryadrenal axis and interleukin-6 activity in children with head trauma and syndrome of inappropriate secretion of antidiuretic hormone. J Pediatr Endocrinol Metab 16: 49-54, 2003.

19. Rochet NM, Chavan RN, Cappel MA, Wada DA, Gibson LE. Sweet syndrome: clinical presentation, associations, and response to treatment in 77 patients. J Am Acad Dermatol 69: 557-564, 2013.

20. Kimura A, Sakurai T, Suzuki Y, et al. Autoantibodies against glutamate receptor epsilon2-subunit detected in a subgroup of patients with reversible autoimmune limbic encephalitis. Eur Neurol 58: 152-158, 2007.

21. Cohen PR. Sweet's syndrome--a comprehensive review of an acute febrile neutrophilic dermatosis. Orphanet J Rare Dis 2: 34, 2007. 
The Internal Medicine is an Open Access article distributed under the Creative Commons Attribution-NonCommercial-NoDerivatives 4.0 International License. To view the details of this license, please visit (https://creativecommons.org/licenses/ by-nc-nd/4.0/).

(C) 2018 The Japanese Society of Internal Medicine

Intern Med 57: 595-600, 2018 